\title{
New Model to Achieve Software Quality Assurance in E-Learning Application
}

\author{
Fatima M. H.Amin ${ }^{1}$, Nadir K .Salih ${ }^{2}$ \\ ${ }^{1}$ Computer Science College, Al-Neelain University, Sudan \\ 2 Department of Electrical and Computer Engineering, Engineering College, Karary University, Sudan
}

\begin{abstract}
Software Quality Assurance (SQA) is an integral part of the software development process and quality of the product. The effectiveness, efficiency of software and respond to user's requirements are the main reason for the success of the products. Software organizes information in the form of operating system, software has two main categories, system software: which control the basic job of computer, and application software: which handles multiple tasks the user needs to do. E-learning is electronic learning delivers learning by internet communication. This Study intends to create E-Learning model with its critical success factors (CSFs) as perceived by university students. Which it can achieve Software Quality assurance in E-Learning application, by simplifies the use of E-learning software and protects the defect in E-learning. The published E-Learning critical success factors are surveyed and grouped into four categories namely, instructor side, student side, system side and interaction of them.
\end{abstract}

Keywords: Software Quality Assurance (SQA), critical success factors (CSFs), and E-learning model.

\section{Introduction}

The E-learning is also called online learning, a computer or computer network is using along with fast growing of information technology has brought a lot of positive impact to the human live, such as business, government, manufacture, and also education. Example of information technology use is E-learning[1]. Technology of ELearning is new and attractive approach for both student and instructor in university and it has taken the place of traditional face to face education environment, there is a great growth of web-based learning media. E-Learning is more attractive for students who are on job and want to continue their education. The flexible nature of $\mathrm{E}$ Learning environment increases learner satisfaction[2]. Quality is most often defined as (fitness for purpose) that is related to the needs of the user wishes and expectations or that the products comply with defined requirements. Also Quality is a functional and artistic measurement used to specify user satisfaction with a product or how well the product performs compared to similar products[3]. Software Quality is the capability of Software product to satisfy stated and implied needs when used under specified conditions (ISO/IEC 25010:2011). Usually, software quality is assessed by means of quality models. Quality can be defined in different ways:

- Excellent with respect to the purpose.

- $\quad$ Satisfies user requirements.

- Suitable price.

- Minimum defects.

- $\quad$ Easy maintenance.

- Faster development.

Software Quality Assurance is very necessary to achieve customer satisfaction and to get a place in the global market. The goals of software quality assurance are to improve software quality by appropriately monitoring both software and the development process to ensure full compliance with the established standards and procedures.[4] Software Quality model is a defined set of characteristics, and of relationship between them, which provide framework for specifying quality requirement and evaluating quality (ISO/IEC 25010:2011). Quality management system requirements are defined in the ISO 9001 standard.

The main goal of these requirements is to satisfy the customer needs, which is the measure of quality software product. Quality improvements affect operations performance in various ways, such as increasing revenue, reducing costs and improving productivity. Quality has been regarded as one of the major drivers of competitive strategy in every industry.

The reason for creating this new model is to achieve high quality in E-Learning application, for both instructor and student. The instructor found that it is easy to deliver subjects and interact with students. The students have more interactions in online learning that are essential to get transfer knowledge.

This paper is organized as follows: In section II, the previous papers being done to study the benefit of software quality assurance and E-Learning models which proposed before and its factors. In section III the model to provide SQA, that contributes in user satisfaction needs. In section IV the SQA factors that help the model to accomplish its task carefully. In section $\mathrm{V}$, the 
Implementation Factors, that which is divided in three products to easy in implementation the model. In section VI, Results for Modeling, show that model is enhancing and helping to achieve the QA in E-Learning. In section VII conclusions are derived.

\section{Related Works}

There are more and more research interests in software quality assurance model because it's very important in software product. In the last decade most of researches deal with software quality assurance and it's important to the society in education, industry, business and also to government. Researcher highlighted the main factors that support the use of E-Learning software technologies, and the benefit of such applications in developing countries as general and in Sudan as a particular situation, toward the achievement of E-Learning goals, the paper discusses will be mainly divided into two main categories [5](The technical factors and Social factors. Presents the Elearning concepts ecosystem, here the propose an Elearning theoretical theory framework which is based upon three principal dimensions: users technology, and services related to E-learning, the classifies the stakeholder groups and their relationship with E-learning system, this theoretical approach integrates learning strategies, technologies and stakeholders[6]. ISO 0126 is the most recognized and applied quality standard to specify and evaluate attributes of the software product, ISO 9126 is extended with the specific characteristic of the E-learning software product, this extension is done by defining the quality characteristics of the E-learning system and integrating them in the ISO 9126 model, result of this study will serve as a basic for the evaluation of an existing system[7]. Presents a model of E-learning in higher education, which is supported by gamification (use of game design elements to motivate user behavior in non-game contexts), the model takes into account modem guidelines for the development of web application and Elearning, E-learning management and important elements of E-learning. The element of user experience and phase of development are presented. With certain modifications, the model can also be applied to other areas of Elearning[8]. The paper is to specify the critical success factors (CSFs) for online distance learning (ODL) in higher education, research methodology was analyzing and synthesizing the literature review. The literatures were reviewed to determine items relevant to online learning success as implementation, criteria and indicator. The results of on the CSFs for ODL can be grouped in to five factors include several important elements that can assist to enhance efficiency of online learning courses in higher education institutions [9]. The goal of this study is to comprehend categorize and inspect prevailing research in Component-based software development (CBSD) field from quality point of view, the paper represented the methodology through which the quality of componentbased software system can be assured. Two main approaches for assuring quality are taken under consideration: encapsulation and composition rules. In this paper, focus is given on two main quality attributes: predictability and reusability, analyze the prior work being prepared for quality assurance and compere the work on the foundational of their research methodology[10]. Quality of software products is often not effectively defined. Some quality models have been proposed, but these conventional models cannot measure and evaluate software product quality comprehensively. To alleviate this problem, ISO/IEC defines international standards called the SQuaRE (System and software Quality Requirements and Evaluation). In the paper, they propose a comprehensive quality measurement framework, which includes a clear measurement plan based on ISO/IEC 25022 and $25023^{1}$. They confirmed the usefulness of their framework by conducting a case study of applying their framework to a commercial software product[11].

\section{Model to Provide SQA}

Software quality models are now a well-accepted means to support quality control of software systems. Many models were proposed that helps to maintain and improve the quality and student can reach required easily and instructor also [12]. The International Organization for Standardization (ISO) was founded in 1946 in order to facilitate international trade, international coordination and unification of industrial standards by providing a single set of standards that would be recognized and respected (Praxiom Research Group).

The ISO 9126 model describing the common characteristics that contributes in the satisfaction of the user's needs that can be:

- The end user: for whom the usability is the most important quality characteristic.

- The software developer for whom the reliability and functionality are the most representative quality characteristics of the software.

- The business manager: for whom the Return on Investment and the sustainability are the main quality factors.

The ISO 9126 quality models was proposed as an international standard for software quality measurement in 1992[7].

\section{Design Factors}

Software quality models factors can be categorized into two different sides; the design factors and implementation factors (As depicted in Fig. 1). 


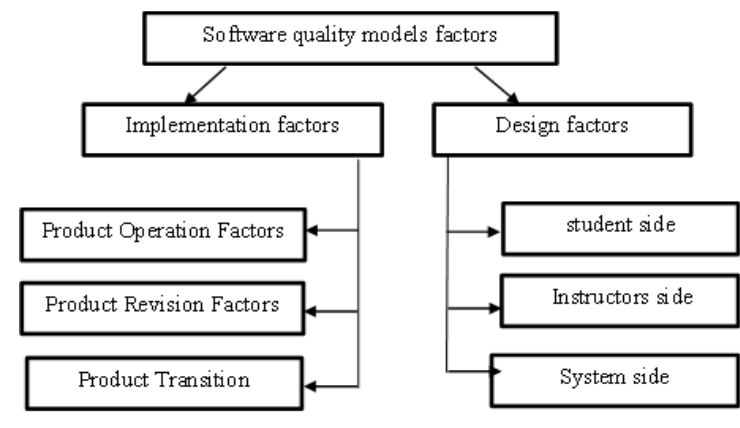

Fig. 1 Design Factor.

The following Fig. 2 shows Software quality models design factors divided into student side, Instructors Side and system side.

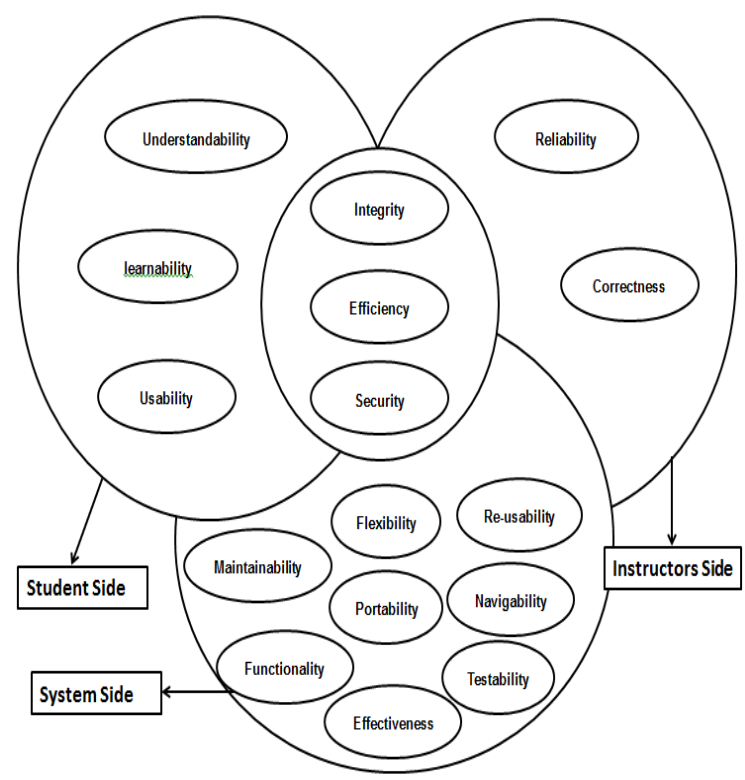

Fig. 2 proposed model

\subsection{Student Side Factors}

Student side operations are performed when student visits the E-Learning system by the internet browser to get information or to solve problem, exercise, to see lectures, text books and all data is received from the instructors. Know a day's Students became fond of technology and all that is related with onion and special learning tools.

\subsubsection{Usability}

Usability is easy to use the Software must be usable, without undue effort, by the type of user for whom it is designed. This means that it should have an appropriate user interface and adequate documentation[12]. The student enjoyable that the system usable, without any difficulties, undue effort to use, designed to whom it is used.

Towards more natural interactive experiences, multimedia components such as audio and video are already being included in current design practice, going beyond the limits of static visual elements and therefore the student found it easy to deal with.

\subsubsection{Learnability}

Learnability means that student can get the knowledge which needs without any difficulties and system play the role of face to face learning in short time and low cost.

\subsubsection{Understandability}

Instructors write the courses in ease way and be suitable for the student level. Code possesses the characteristic understandability to the extent that its purpose is clear to the student.

\subsection{Instructors Side Factors}

Instructor side plays a central role in the effectiveness and success of E-Learning based courses, determined the benefit subjects and made up to date.

\subsubsection{Reliability}

A set of software attributes with ability to maintain its specific level of performance under the specific stated conditions for a stated period of time.

Requirement deal with failures to provide service, they determine the maximum allowed software system failure rate, and can refer to the entire system or to one or more of its separate functions. Reliability tests measure the ability of the system to keep operating for a long time without developing failure. Ability to perform the promised service dependably and accurately.

\subsubsection{Correctness}

The extent to which a program satisfies its specifications and fulfills the student's mission objectives.

\subsection{System Side Factors}

Technology plays important roles in delivering learning outcomes because student has more interactions in online learning environments that are essential to be successful. We mean by infrastructure the information technology and university support, which they play fundamental role in E-learning. The most attractive feature of E-Learning according to student and instructor both is its flexibility of location and time. Commuting was the main problem for 
students in traditional classes E-Learning come with new virtual (anywhere - anytime - anyplace). It can be classify as follow:

\subsubsection{Testability:}

Testability requirements for the ease of testing are related to special features in the program that help the tester, for instance by providing predefined intermediate results and $\log$ files. The goal of increasing the testability of software is not just to detect defects but more importantly, to detect defects as soon as they are introduced. Thus, reducing the cost and time to fix the bug and reducing higher quality each build of the release it is important to be able to verify every requirement, both explicitly stated and simply expected. Testability means the ability to verify requirements.

\subsubsection{Flexibility}

The process ability to deal with changes. The ease with which a system or component can be modified for use in applications or environments other than those for which it was specifically designed Flexibility normally refers to the ability for the solution to adapt to possible or future changes in its requirements. When you design or build a solution you should try to cater for these changes, which inevitably arrive in the future.

\subsubsection{Functionality}

A set of software attributes with specific properties that provide functions that satisfy the needs of the user.

\subsubsection{Portability}

It can be described as the property that supports migration of component from one system to another with little or no modifications.

\subsubsection{Effectiveness}

It allows us to perform our tasks quickly and proficiently. Effective is successful in reaching learning objectives, easy accessibility, consistent and accurate message, easy to use, entertaining, memorable, relevant and reduced training costs. Effectiveness is measured by the software's correctness and the accuracy achieved when performing specific goals.

\subsubsection{Re-usability}

It requirements deal with the use of software modules originally designed for one project in a new software project currently being developed.

\subsubsection{Maintainability}

It is the set of attributes that bear on the effort needed to make specified modifications. Easy to understand, modify and retest.

\subsubsection{Navigability}

It is the ease of student's quick and efficient access to the content, and ease for them to get the knowledge, lectures, exercise and subjects related to their study.

\subsection{Student Side \& instructors Side and} technological infrastructure side Intersections

\subsubsection{Security}

Confidentiality integrity, Non-repudiation, Accountability, Authenticity. It refers how the software is able to control the unauthorized access to the services provided to it. The freedom form dinger, risk OR doubt (Confidentiality, Physical safety, financial safety).

\subsubsection{Efficiency}

A set of software attributes that represents the ability of the software product to provide relationship between level of performance of the software and the amount of recourses that are used under the stated conditions.

\subsubsection{Integrity}

Integrity requirements deal with the software system security; it is the requirement that data and process be protected from unauthorized modification.

\subsubsection{Ethics}

It is important factor in quality is the ethics that the website does not attack a religious community or geographical areas or working on the immorality and corruption and encourage hatred between human beings and of the regions cannot be there the quality of the content provided through this site versa must be served Services serve the human way or optimal content helps to be fraudulent to users and we must be mindful of our ethics offices with all segments of society and his message to be Semitic, and that does not use user information to expose their affairs. And the developers and user are having the same Responsibility.

\subsubsection{Privacy}


Privacy requirements specify how data privacy is to be maintained, As the Web provides many mechanisms to interlink data across systems. It is important that it keeps the possibility for users, that want or need it, to keep their personal information private and scattered.

\subsubsection{Interoperability}

Interoperability it is attribute of the software that provides a structure of highly independent modules. Interoperability of one system to another should be easy for product to exchange data or services with other systems.

\section{Implementation Factors}

The following table shows Software quality models implementation factors divided into Product Operation (How well it runs), Product Revision (How well it can be changed, tested, and redeployed) and Product Transition (How well it can be moved to different platforms and interface with other systems).

Table 1: Implementation Factors

\begin{tabular}{|l|l|l|}
\hline $\begin{array}{c}\text { Product } \\
\text { Operation factor }\end{array}$ & $\begin{array}{c}\text { Product Revision } \\
\text { factor }\end{array}$ & $\begin{array}{c}\text { Product Transition } \\
\text { factor }\end{array}$ \\
\hline Correctness & Maintainability & Portability \\
\hline Efficiency & Flexibility & Reusability \\
\hline Reliability & Testability & Interoperability \\
\hline Integrity & & \\
\hline Usability & & \\
\hline
\end{tabular}

\section{Results for Modeling}

It is clear that model is enhancing and helping to achieve the Quality Assurance in E-Learning, in work between the students and constructors in the same, the model less than from the critical stage in life cycle the services so all parties of the model are very important Student Side, instructors Side, system side and the Intersections of all sides with each anther to achieving the Quality Assurance. The proposed model eases the development in software, help in managing software quality assurance because there is intersection between the factors of instructors, student and systems sides, minimize the problems and defects in software, and also decrease the financial loss.

\section{Conclusion}

This paper addresses the Software Quality model factors in E-Learning application, the factors are divide into two: design factor and implementation factor. Design factor has three sides; student, Instructors and system sides. The implementation factor has three product factor; Product Operation, Product Revision and Product Transition. The different factors are discussed according to its impact on E-learning applications.The main of this study is to create a new model to simplify the software of E-learning.

\section{References}

[1] A. H. Rohayani, A Literature Review: Readiness Factors to Measuring e-Learning Readiness in Higher Education. Procedia Computer Science, 2015. 59: p. 230-234.

[2] M.W. Malik, Factor Effecting Learner's Satisfaction Towards E-Learning: A Conceptual Framework. OIDA International Journal of Sustainable Development, 2010. 2(3): p. 77-82.

[3] A. Sharma, A. Kalia, and H. Singh, The software quality assurance framework for CBSD. International Journal of Advanced Research in Computer Science and Software Engineering, 2012. 2(11): p. 161-170.

[4] A.T. Quadri, M. Abubakar, and M. Sirshar, Software quality assurance in component based software development-A survey analysis. International Journal of Computer and Communication System Engineering, 2015. 2(2): p. 305315.

[5] H.A.A Alamin, and E.E.A. Elgabar, Success Factors for Adopting E-learning Application in Sudan. 2014. 3(6): p. 128-131.

[6] M. Aparicio, F. Bacao, and T. Oliveira, An e-Learning Theoretical Framework. Journal of Educational Technology \& Society, 2016. 19(1): p. 292-307.

[7] R. Djouab, and M. Bari, An ISO 9126 Based Quality Model for the e-Learning Systems. International Journal of Information and Education Technology, 2016. 6(5): p. 370.

[8] M. Urh, G. Vukovic, and E. Jereb, The model for introduction of gamification into e-learning in higher education. Procedia-Social and Behavioral Sciences, 2015. 197: p. 388-397.

[9] B. Cheawjindakarn, P. Suwannatthachote, and A. Theeraroungchaisri, Critical success factors for online distance learning in higher education: A review of the literature. Creative Education, 2013. 3(08): p. 61.

[10] P. Kaur, and N. Batolar, A Review on Quality Assurance of Component-Based Software System. IOSR Journals (IOSR Journal of Computer Engineering), 2015. 1(17): p. 53-57.

[11] H. Nakai, et al., Evaluating Software Product Quality based on SQuaRE Series. 2016.

[12] E.K. El-Rayyes, and I.M. Abu-Zaid, New Model to Achieve Software Quality Assurance (SQA) in Web Application. International Journal of Science and Technology, 2012. 2(7).

[13] B. Dugalic, and A. Mishev. ISO Software Quality Standards and Certification. in BCI (Local). 2012. Citeseer.

[14] A. Koka, Software Quality Assurance in Scrum Projects: a case study of development processes among scrum teams in South Africa, 2015.

[15] M. C. Lee, Software Quality Factors and Software Quality Metrics to Enhance Software Quality Assurance. British Journal of Applied Science \& Technology, 2014. 4(21): p. 3069-3095. 